\title{
DEVIATION ANALYSIS AS A CONTROL METHOD
}

\author{
G. Ganeva* \\ Department of Industrial Business, University of National and World Economy, Sofia, Bulgaria
}

\begin{abstract}
The article focuses on the management approach in the assessment and analysis of deviations in operating enterprises and technically explains the methodology for calculating deviations. The types of cost deviations and their monitoring in enterprises are determined, as a deviation of the costs for direct materials, a deviation of the costs for direct labor, etc.

Attention is given to the main reasons for cost deviations such as the cost of materials, downtime, labor efficiency and more.

PURPOSE: The aim of the article is to identify and analyze existing technical and methodological approaches for calculating deviations.

METHODS: The systemic and structural approach, the analysis and the synthesis, including the study of literature sources.

RESULTS: The contributions are about choosing the right tools for determining and assessing deviations and the reasons for them in the analysis with specific digital information.

CONCLUSION: It is found that controlling as part of cost management and analysis of variances helps to identify specific measures and eliminate errors through them.
\end{abstract}

Key words: cost management, management approach, budgeting, budget, direct costs, production

\section{INTRODUCTION}

Cost management is one of the main functions in the management of modern enterprises. Cost management is associated with the application of management functions (planning, organizing, directing and controlling) in relation to the costs of the enterprise. It is expressed in the ability to save resources, and maximizing their use. (1)

Cost is an estimate of the price to be paid for a product based on the cost of creating the product. (2)

In connection with the consideration of controlling as a function of cost management, it supports decision-making and the nature of the functions of controlling determines its important role for the successful development of the enterprise. (3)

\footnotetext{
*Correspondence to: Gergana Ganeva, Department of Industrial Business, University of national and world economy - Sofia, Sofia, Bulgaria,gganeva94@gmail.com
}

The importance of cost management increases with the need to monitor various deviations between planned (budgeted) and actual (realized) costs through analysis and control. In such cases, it is important to analyze the deviations and determine the reasons for these differences. In order to obtain a satisfactory answer for the deviations, it is necessary to analyze first the influence of the individual parameters with cost elements, and then their complex influence on the deviations.

Of interest in this issue is the analysis of the reasons for these deviations of costs and the factors that affect them.

Regardless of the established theoretical completion of research in the field of cost management, the emphasis should be on the management approach in the assessment, analysis, and control of cost deviations in operating enterprises. This requires managers to seek and use modern and flexible cost management methods. In this regard, the behavioral approach of managers is important 


\section{GANEVA G.}

in assessing the importance of deviations and highlighting the influencing factors in choosing management decisions.

The subject of research in the article is defined as the system for Cost Management in terms of deviations and control, as well as the set of management approaches, part of the management process.

The research questions that are addressed:

First, a study of the types of deviations by cost elements - deviation of direct material costs and direct labor costs.

Second, taking into account favorable and / or unfavorable deviations and the reasons for them.

Third, outlining the factors influencing the elimination of deviations.

The research thesis is:

Cost management and determination of the types of deviations are successful under the condition of continuous analysis, updating and control in the overall cost management system, incl. deviation analysis. To establish the deviations of the actual costs from the budgeted ones, they must be analyzed.

Deviation analysis is a method of control through which the causes of deviations and the factors that have affected can be identified controllable and uncontrollable.

Deviation analysis and control are elements of cost management and the overall management system of the enterprise.

The following working definitions are derived from the theoretical study:

- „Cost management is broadly defined and includes the process of identifying, reporting, planning, calculating, analyzing and controlling costs in the enterprise."; (4)

- The deviation is the difference between the budgeted and the actual costs incurred;

- Deviation analysis is the process by which the overall difference between budgeted and actual results is analyzed;

- Management control is the management and control of production costs by deviations. It is associated with the use of the tools of normative calculation.

1. Deviation analysis and control
When analyzing the main deviations, managers should consider the main differences that have been obtained and use the results for the analysis of deviations as a method of control.

When in the analysis of deviations as a method of control it is established by the managers that the actual results are better than the expected results, we have a favorable deviation. If the actual results are worse than expected, we have an unfavorable deviation.

In the analysis of the deviations, deviations in the following cost elements can be observed:

- Deviation of the cost of direct materials the difference between what the production actually costs and what it should cost. The deviation of the cost of direct materials can be subdivided into:

- the deviation of the price of direct materials;

- the deviation of the use of direct materials.

- Deviation of direct labor costs - the difference between what the production of the product should cost in terms of labor input and what it actually costs. The deviation of direct labor can be subdivided into:

- the deviation of the norm of direct labor;

- the deviation of the efficiency of direct labor.

- Deviations of variable overhead costs - the difference between the amount of variable overhead costs that should be incurred in the actual hours of active work and the actual amount of variable overhead costs that have been incurred.

The methodological approach and tools for calculating the variances of variable costs are essentially the same for labor, materials and variable overhead costs;

- Deviations of fixed overhead costs - are an attempt to explain the incomplete absorption or over-utilization of fixed overhead costs.

The chosen approach in the article focuses on the deviations of the costs for direct materials and direct labor, without considering the deviations of the sales and the deviations of the general production costs (fixed and variable).

2. The deviation of direct material costs will be divided as:

- Deviation of the price of direct materials;

- Deviation from the use of direct materials. 
The deviation of the price of direct materials is the difference between the price and the costs expressed in the cost of the actual quantity of material that is used or purchased.

The deviation of the use of direct materials is the difference between the amount of material that should have been used and the amount of material that has been used.

The actual research will use a methodological approach and tools proposed by Assoc. Prof. D. Andreeva (5)

For the production of a product, for example, a dress, company " $\mathrm{X}$ " makes the following cost for direct materials:
Used materials:

GANEVA G.

3 square meters of material were used at a price of BGN 10 per square meter $=\mathrm{BGN} 30$ per dress.

Manufactured:

During the period, 4,000 pieces were produced, using 13,000 square meters of material, for which BGN 125,000 was paid.

The methodological approach in the analysis of deviations includes the following stages and steps:

Step 1 - deviation of the price of direct materials;

Step 2 - deviation from the use of direct materials.

Table 1. Solution of the problem

\begin{tabular}{|c|c|c|}
\hline$(1)$ & Deviation of direct materials & \\
\hline & \multicolumn{2}{|c|}{ The difference between what was planned 4,000 units to cost and what they actually cost. } \\
\hline & & BGN \\
\hline & 4,000 units should cost (x30 BGN) & 120000 \\
\hline & but they were really worth & 125000 \\
\hline & Total deviation of direct materials & $5000^{1}$ \\
\hline & \multicolumn{2}{|l|}{ The deviation is unfavorable because the units cost more than planned. } \\
\hline & \multicolumn{2}{|l|}{ The deviations of the direct materials regarding their price and their use will be traced. } \\
\hline \multirow[t]{7}{*}{ (2) } & Deviation in the price of direct materials & \\
\hline & \multicolumn{2}{|c|}{$\begin{array}{l}\text { The difference between what they planned } 13,000 \text { square meters to cost, and what they } \\
\text { actually cost. }\end{array}$} \\
\hline & & BGN \\
\hline & 13,000 square meters is planned to cost (x10 BGN) & 130000 \\
\hline & but they were actually worth & 125000 \\
\hline & Deviation of the price of the material & $5000^{2}$ \\
\hline & \multicolumn{2}{|l|}{ The deviation is favorable because the material costs less than planned. } \\
\hline \multirow[t]{8}{*}{ (3) } & Deviation in the use of direct materials & \\
\hline & \multicolumn{2}{|c|}{$\begin{array}{l}\text { The difference between how many square meters of material was planned to be used to } \\
\text { produce } 4,000 \text { units and how many square meters were actually used, the cost is per square } \\
\text { meter }\end{array}$} \\
\hline & for 4,000 units is planned to be used (x3 sq. m) & 12 000sq.m \\
\hline & but in reality were used & 13 000sq.m \\
\hline & Deviation of use in sq. $\mathrm{m}$ & $1000^{1}$ \\
\hline & $\mathrm{x}$ price per sq. $\mathrm{m}$ & $10 \mathrm{BGN}$ \\
\hline & Deviation of use in BGN & $10000 \mathrm{BGN}^{1}$ \\
\hline & \multicolumn{2}{|l|}{ The deviation is unfavorable because more material was used than planned. } \\
\hline (4) & Summary & BGN \\
\hline & Price deviation & $5000^{2}$ \\
\hline & Deviation in use & $10000^{1}$ \\
\hline & Deviation & $5000^{1}$ \\
\hline & Note: (2) shows a favorable deviation and (1) an unfavorable one & \\
\hline
\end{tabular}

\subsection{Reasons for variations in material costs}

This analysis must take into account a wide range of possible reasons for the deviations in the price of materials.
The favorable deviation in the price of direct materials in this case may be the result of one or more reasons, such as: 
- It was agreed with the supplier a price for the direct materials lower than planned in the budget;

- The supplier has been changed;

- Larger quantities were purchased than planned, so a discount was made;

- An unexpected drop in the prices of direct materials may be due to oversaturation of the market;

- The purchased materials are of lower quality.

What should be the management approach and how to assess the reasons?

If it is from ordered larger quantities of materials than budgeted, for which the manager has received a discount, the approach is as follows:

To determine whether the purchase of these larger quantities has led to higher storage costs. If the storage costs exceed the discount, the deal was not profitable. To avoid this problem, some companies have previously limited the size of storage spaces for materials to the one that is needed.

Table 2. Solution of the problem

\begin{tabular}{|c|c|c|}
\hline (1) & Deviation in direct labor & \\
\hline & $\begin{array}{l}\text { The difference between what were } 4,000 \text { units budgeted to cost and what } t \\
\text { cost. }\end{array}$ & hey actually \\
\hline & & BGN \\
\hline & 4,000 units are budgeted to cost (x15 BGN) & 60000 \\
\hline & but they were actually worth & 90000 \\
\hline & General deviation of direct labor & $30000^{1}$ \\
\hline & The deviation is unfavorable because the units cost more than planned. & \\
\hline & $\begin{array}{l}\text { The deviations of direct labor regarding their norm and their efficiency will } \\
\text { be monitored. }\end{array}$ & \\
\hline$(2)$ & Deviation from the norm of direct labor & \\
\hline & The difference between what is budgeted 4,500 hours to cost and what they act & lally cost. \\
\hline & & BGN \\
\hline & 4,500 hours of work are planned to cost (x15 BGN per hour) & 67500 \\
\hline & but they were actually worth & 90000 \\
\hline & Deviation from the norm of direct labor & $22500^{1}$ \\
\hline & The deviation is unfavorable because labor has costed more than it is budgeted & o cost. \\
\hline (3) & Deviation from the efficiency of direct labor & \\
\hline & 4,000 units are planned to be needed (x1 hours) & 4 000hours \\
\hline & but in reality were necessary & 4 500hours \\
\hline & Deviation in the efficiency of hours & 500hours ${ }^{1}$ \\
\hline & $\mathrm{x}$ hourly rate & $\mathrm{x} 15 \mathrm{BGN}$ \\
\hline & Deviation in the efficiency in BGN & $7500^{1}$ \\
\hline & $\begin{array}{l}\text { The deviation is unfavorable because more hours have been worked than } \\
\text { were planned. }\end{array}$ & \\
\hline & Summary & BGN \\
\hline & Deviation from the norm & $22500^{1}$ \\
\hline & Deviation of efficiency & $7500^{1}$ \\
\hline & Total deviation & $30000^{1}$ \\
\hline & Note: (1) indicates an unfavorable deviation. & \\
\hline
\end{tabular}

Regarding the reported unfavorable deviation and the established reason - the use of more materials than planned, the following reasons can be highlighted:

- Defective materials;

- Excessive waste;

- Wastes from cutting the material;

- Obtained unforeseen differences in the used materials compared to the set (planned).

3. The deviation of direct labor costs

The budgeted direct labor costs of a product a dress are as follows:

For 1 hour of work at BGN 15. per hour the price is $=$ BGN 15 per dress. During the period, 4,000 dresses were produced and the direct labor costs were BGN 90,000 for 4,500 hours of work.

Direct labor costs and variances can be analyzed as:

A) The deviation of direct labor;

B) The deviation of the norm of direct labor;

C) The deviation of the efficiency of direct labor. 
The reasons for the unfavorable deviations in the efficiency of production labor presented in the table (Table 2) may be due to one or more of the following reasons:

- Low-skilled workers;

- Inefficient schedule for the production process;

- The machines are not maintained in a timely manner.

The management approach in case of untimely maintenance of the machines is for the company to appoint a team composed of engineers and machine operators, to create a schedule for regular inspection of the equipment, which will improve labor productivity and product quality.

4. Efficiency deviations - The deviation in efficiency is the difference between the inputs (materials and labor) that are actually used and the investments that should be used in production. From this it can be pin pointed that for the company to be effective she should use as much as or less than it was planned but never more. (6)

The tables (Table 1 and 2) show two kinds of unfavorable deviations in efficiency - in both direct costs of materials and labor. The reason is that more resources have been used than the ones that have been planned in the budget. That caused a decrease in the operating profits.

\section{CONCLUSION}

The finding of deviations of the actual from the planned results should not interpret the controlling as inertia in the management of the business units and in particular in the management of the expenses. It is not aimed at the "culprit", but how to do it and what measures to eliminate the mistakes to identify.

\section{REFERENCES}

1. Lambovska, M., Enterprise Cost Management, Trakia - M, Sofia, 2009, p. 23.

2. Oxford Advanced Learner's Dictionary of Current English, III ed., Oxford University Press, 1987.

3. Simeonov, Ogn., Controlling. Fundamentals of Controlling and Operational Controlling, Trakia - M, Sofia, 2004, pp. 13-14.

4. Iliev, J., Competitiveness of the Bulgarian Industrial Companies, University Edition "Economy", Sofia, 2005, p. 195.

5. Andreeva, D., Cost Management. Theory, methodology, practice. Publishing Complex - UNWE, Sofia, 2013, pp. 149-153.

6. Horngren, Charles T., Datar, Srikant M., Foster, G., Cost Accounting, A Managerial Emphasis, Eleventh Edition, 